IZA DP No. 6867

Grades, Aspirations and Post-Secondary Education Outcomes

Louis N. Christofides

Michael Hoy

Joniada Milla

Thanasis Stengos

September 2012 


\title{
Grades, Aspirations and Post-Secondary Education Outcomes
}

\author{
Louis N. Christofides \\ University of Cyprus, \\ University of Guelph and IZA \\ Michael Hoy \\ University of Guelph \\ Joniada Milla \\ University of Guelph \\ Thanasis Stengos \\ University of Guelph
}

\section{Discussion Paper No. 6867 \\ September 2012}

IZA

\author{
P.O. Box 7240 \\ 53072 Bonn \\ Germany
}

\author{
Phone: +49-228-3894-0 \\ Fax: +49-228-3894-180 \\ E-mail: iza@iza.org
}

Any opinions expressed here are those of the author(s) and not those of IZA. Research published in this series may include views on policy, but the institute itself takes no institutional policy positions. The IZA research network is committed to the IZA Guiding Principles of Research Integrity.

The Institute for the Study of Labor (IZA) in Bonn is a local and virtual international research center and a place of communication between science, politics and business. IZA is an independent nonprofit organization supported by Deutsche Post Foundation. The center is associated with the University of Bonn and offers a stimulating research environment through its international network, workshops and conferences, data service, project support, research visits and doctoral program. IZA engages in (i) original and internationally competitive research in all fields of labor economics, (ii) development of policy concepts, and (iii) dissemination of research results and concepts to the interested public.

IZA Discussion Papers often represent preliminary work and are circulated to encourage discussion. Citation of such a paper should account for its provisional character. A revised version may be available directly from the author. 
IZA Discussion Paper No. 6867

September 2012

\section{ABSTRACT}

\section{Grades, Aspirations and Post-Secondary Education Outcomes}

We explore the forces that shape the development of aspirations and the achievement of grades during high school and the role that these aspirations, grades, and other variables play in educational outcomes such as going to university and graduating. We find that parental expectations and peer effects have a significant impact on educational outcomes through grades, aspirations, and their interconnectedness, an issue explained in the context of a rich, longitudinal data set. Apart from this indirect path, parents and peers also influence educational outcomes directly. Policy measures that operate on parental influences may modify educational outcomes in desired directions.

JEL Classification: $\quad$ 120, J00

Keywords: $\quad$ university attendance, aspirations, peers, parents, Canada

Corresponding author:

Joniada Milla

Department of Economics and Finance

University of Guelph

Guelph, ON N1G 2W1

Canada

E-mail: jmilla@uoguelph.ca

\footnotetext{
* While the research and analysis are based on data from Statistics Canada, the opinions expressed do not represent the views of Statistics Canada.
} 


\section{Introduction}

The importance of education in general and post-secondary education (PSE) in particular in the process of individual human capital acquisition and fulfillment, the externalities that stem from PSE and the significance of this fabric of knowledge for the process of economic growth are now well accepted. Apart from the many theoretical explorations, a large empirical literature has emerged. The empirical explorations focus on a number of important issues. Studies of the determinants of university attendance link the PSE decisions of children to their cognitive and non-cognitive ability, their other characteristics, and the characteristics of their family (Day, 2009) (Day, 2009; Frenette, 2009). Others explore important gender dimensions (Jacob, 2002; Frenette and Zeman, 2007; Christofides et al., 2008). Some other studies focus on the important role of parental education and income (see Zhao et al., 2003; Johnson and Rahman, 2005; Knighton and Mirza, 2002; Finnie and Mueller, 2008, among many others). Apart from own individual and parental characteristics, the empirical literature provides evidence that friends in school, in the neighborhood, and in the work environment influence the behavior and decision-making of individuals including the decision to drop out of high school (see Foley et al., 2009), the decision to pursue PSE education, as well as decision-making in many social contexts (smoking, drinking alcohol, taking illegal drugs, committing crimes, and engaging in safe or unsafe sexual practices). The literature has yet to achieve a consensus on whether peer effects are significant and whether they are causal. How one goes about disentangling identification issues in peer effects, for any specific application, is driven in part by data availability. In our study we have a variety of quality characteristics of children that we can access in order to study peer effects. We use student-elicited characteristics of their group of peers, which potentially measure peer influences more effectively and are better proxies in terms of sampling and measurement error than the peer variables commonly used in the literature. These are constructed as an aggregate of students' characteristics in the classroom, school, etc. 
Entry into PSE in general and university ${ }^{1}$ in particular is paved through the motivation or aspiration to attend university and the achievement of a high enough grade point average (GPA), mechanisms which are subject to common but also separate forces (thus providing identification). These mechanisms influence each other but also condition ultimate outcomes such as going to university. The path to university involves aspirations and achievement through high school, requiring longitudinal data to study it. The Youth in Transition Survey - Cohort A (YITS-A), a Statistics Canada data set, provides the information needed to explore the high school experience leading up to PSE outcomes. In this paper we exploit the longitudinal nature of YITS-A and the wealth of student, parental, peer and other variables that it contains to study the web of high school aspirations, grade achievement and eventual PSE outcomes. We analyze the role of parental and peer variables in determining student aspirations about further education and their high school performance. We then investigate how these aspirations and grades affect university attendance. We recognize the simultaneity involved between aspirations and grade achievements and use the wealth of data available in YITS-A to select instruments to deal with it. We also recognize and exploit the temporal separation between high school aspirations/grade achievements and PSE outcomes when estimating outcome equations. Different from existing research in this area, which generally examines these issues at a point in time and often using data from a single institution (school or university), we are able to conduct a longitudinal analysis with data from several schools in Canada, thus accounting for the "historical" factor (Hanushek et al., 2003) in the aspirations updating process and decision making leading to university attendance. Also, as in Black et al. (2010), we analyze the peer effects on these children while teenagers, which it is often argued to be an age when they are most affected by their friends. Additionally, we are not limited to test peer effects on GPA attainment; we are also able to study their influence on student decisions to attend university and to

\footnotetext{
${ }^{1}$ In the Canadian educational system a college is comparable to the US junior colleges. Most university undergraduate programs are four years but it is possible to graduate with a "general", three-year degree.
} 
complete a degree.

Our findings suggest that the influence of closest friends and/or classmates as well as parents is pervasive. These groups affect the aspirations for university and grade performance while students are in high school. But they also affect eventual outcomes, such as university attendance or completion, directly and beyond any effects they may have had at the intermediate stage on high school aspirations and grades. That is, they have direct effects on outcomes as well as indirect ones, through aspirations and grades which themselves influence outcomes. These influences are conditioned by income group and gender. We believe that these effects are well established and net of the reflection problem, sample selection problem and correlated effects that have been identified in the literature.

From the perspective of a policy goal to increase PSE attendance, it would appear that the influence that parents have on children could be enhanced by providing expert counseling about the advantages of PSE not only to students but also to their parents. Based on our results, such policy measures should focus on children of low-income families because it is likely that the impact will be larger on this group.

The paper is organized as follows. We discuss the data and methodology in Sections 2 and 3, respectively. We analyze our empirical results in Section 4 and conclude in Section 5.

\section{Data}

\section{Sampling Characteristics}

The source of the dataset we use is the YITS-A, a biennial longitudinal survey of 5 cycles. It follows the students involved from age 15 to 23 , from year 2000 to 2008 with interviews taking place in the spring of every two years of the time span indicated (see Table 1). In the first cycle, students as well as their parents and school principals were interviewed. The first cycle of this dataset merges with the survey of the OECD Programme for International Student Assessment (PISA). Beginning with 
the second cycle, the students only are interviewed. The definitions of the variables we use in this empirical work are provided in detail in the Appendix. Given that the survey initially interviews only 15-year old students, most of them (93\%) are registered in the same grade level. In our subsample we have 710 high schools with eleven students per school on average. Sampling in YITSA was conducted based on a two-stage probability sampling. In the first stage the high schools were chosen, and in the second stage the students within each school were chosen. For student population representation purposes we use probability weights in all our estimations. Since the stratum in this survey is the school, we use robust standard errors clustered by school.

\section{Own, Parental and School Characteristics}

In order to account for the heterogeneity across individuals, we control for a set of variables measuring a student's own characteristics, peer characteristics, family background and parental characteristics, school and teacher characteristics. The students own characteristic variables include the PISA reading score at age 15, hours spent working on homework in free time outside of school and an indicator of whether the student reports that a university degree is needed to work in the future job where the student plans to work at the age of 30 . The PISA reading score is considered a reasonable proxy for cognitive abilities (Foley et al., 2009) having controlled for the GPA (Frenette, 2009). We use reading test scores of PISA, rather than math or science test scores, because the number of students writing it is higher by about fifty percent than the math and science PISA tests.

The school and teacher variables include a comprehensive set of indicators measuring different aspects of the teaching quality of high schools. These include school size, the percent of female students in the school, "Teacher quality", "Instructional time", "Quality of school physical infrastructure", "Quality of school's material educational resources", "Teacher-related factors affecting school climate", "Student-related factors affecting school climate", "Grade-level average GPA" and "Grade-level average aspirations" which play the role of fixed effects by accounting for 
the general socio-economic level of the students in each school and for the fact that some schools may be more generous in grading but others not; "Teachers' morale and commitment", "Teacher shortage" and lastly the variable "Government-independent private", which accounts for differences in the academic achievement and expectations for future education of the students who attend these schools (Day, 2009).

Parents may influence their children's academic achievement and aspirations in several ways. The ability of parents to help finance their children's PSE is a plausible reason why a low family income may be a barrier to PSE. Income levels could also reflect many other indirect influences. For example, higher-income families may spend more on the nurturing of children in ways that allow them to better develop the cognitive and non-cognitive skills that condition successful entry into PSE. This process starts in childhood and continues into the teenage years. Another indirect influence might be through the general social environment which differs, on average, across income classes and the education level of parents. Parental education may also be a signal of innate ability that is inherited by children. Hence, in our specifications we control for parental education and household income per capita. In our dataset, apart from the above mentioned, we have further information about parents and the student's family background. Other variables are "Sibling dropout", "Parent(s) immigrant", "Non-birth parent", "Parent(s) view of PSE important", "Parents' nurturance behavior", "Parents' monitoring behavior", "Family educational support" and "Residence region indicators".

"Parental expectations" is an indicator variable of whether the parents expect the child to attain at least one university degree in the future. Unlike the peer effect variables considered in this paper, family is a non-overlapping social group when it comes to parental expectations. This feature helps identification. Do parental expectations reflect the ability of the child or just the desire of the parent for his/her child's education? We are inclined to support the interpretation that the parental expectations variable reflects the ambition of the parent for the child rather than the child's ability. 
In making this statement we rely on the answers to a question in the survey asked to the parent right after the question about his/her expectations on the educational attainment of the child. The question is: "What is the main reason you hope child will get this level of education" and among the responses, $68.6 \%$ of the parents responded "Better job opportunities or pay" and "Valuable for personal growth and learning" and only 9.8\% responded that "Best match with child's ability".

Aiming to capture the influence of peers, we use several peer variables most of which are selfreported by the student and one is a grade-level averaged variable. The self-reported variables are the following. "Friends smoke" might be indicating general social attitudes. A teenager of age 15 who has made smoking a habit may be more likely to show negativity towards school and/or reflect an overall rebellious attitude. "Friends think it okay to work hard" is a variable capturing the fact that good students may face some negative behavior from their classmates such as being called a "nerd" or "teacher's pet" (Cooley, 2007; Foley et al., 2009). "Friends think completing HS is important" and "Friends think going to PSE" serve as indicators of the general aspirations of the close group of friends towards education. There are both advantages and disadvantages to these variables. On one hand, we have no information about the "close group of friends". Nevertheless, it is likely that most of them are friends from the neighborhood and thus attend the same high school as the reference student. On the other hand, being reported by the students themselves, these variables are perceptions about their closest friends and the peer pressure that the students feel to be affected by the most. This is a valuable characteristic of the elicited variables. The standard way of constructing a peer variable is using the mean of the characteristics and/or outcomes of the group of friends excluding the reference student (Ammermueller and Pischke, 2009; Vigdor and Nechyba, 2005; Lee, 2007, among many others). We construct one variable in this way, "Grade-level average PISA" which captures the influence of the cognitive ability of the classmates on student $i$. In high school, children typically have different classmates in each course/class and so a purer measure of classmate peer effect is not necessarily desirable. However, the "quality" of children in the same 
year of schooling is closer than using the "quality" of children in the entire school.

\section{Methodology}

The analysis is conducted separately for two periods: the PSE years, when students are 19-23 years old (cycles 3-5 of the survey), and the high school period when students are 17 years old (cycle 2 of the survey). For the PSE years we estimate the following equation:

$$
\text { Out }_{i s, c}=\alpha_{1} A_{s p_{i s, c-1}}+\alpha_{2} G P A_{i s, 18}+\operatorname{Peers}_{i s, 15} \beta+\gamma \text { ParentExp } i s, 15+X_{i, c-1} \theta+\varepsilon_{i s, c}
$$

The outcome of student $i$ in school $s$ and cycle $c\left(\right.$ Out $\left._{\mathrm{is,c}}\right)$ is modeled as a function of the aspirations to attend university dating one cycle earlier or two years earlier $\left(\operatorname{Asp}_{\mathrm{is}, \mathrm{c}-1}\right)$, high school overall grade at age $18\left(\mathrm{GPA}_{\mathrm{is}, 18}\right)$, a vector of peer effects $\left(\right.$ Peers $\left._{\mathrm{is}, 15}\right)$, parental expectations $\left(\right.$ ParentExp $\left.\mathrm{is}_{\mathrm{is}, 15}\right)$ both at age 15 and a vector containing a comprehensive set of predetermined control variables, $\mathrm{X}_{\mathrm{i}, \mathrm{c}-1} \cdot \varepsilon_{\mathrm{is,c}} \mathrm{is}$ a $\mathrm{N}(0,1)$ error term. We use two definitions of PSE outcome: (i) "Attended university" at ages 19, 21, 23 separately and (ii) "Graduated university" at age 23. Among other issues, this specification explores whether peer pressure and parental influences during high school have any effect beyond their effect on grades and aspirations on actual university attendance and university degree completion.

Students are evaluated based on a set of credentials for access to an undergraduate university program. One of the main requirements of Canadian universities is the GPA threshold. Hence, a GPA higher than the threshold would make a student eligible to attend universities but also motivate him towards this decision. The earlier the student has this intention, the more willing he would be to study harder to increase his GPA so that he may enter the program and be accepted by the university he desires. Accordingly, if a higher GPA is achieved during high school, it will induce a revision upwards of aspirations and so on. Thus, not only might grades affect aspirations, but aspirations may also affect grades. Based on this idea, we have two simultaneous reduced form equations to be 
estimated at age 17 when the students are still in high school ${ }^{2}$. Equation (2) below specifies the probability to achieve a high school GPA higher than $70 \%$ at age 17 as a function of aspirations to attend university at 17 and "High school GPA", peer effects and "Parental Expectations" and a set of control variables all at age 15 .

$$
G P A_{i s, 17}=\alpha_{1}^{\prime} A s p_{i s, 17}+\alpha_{2}^{\prime} G P A_{i s, 15}+\operatorname{Peers}_{i s, 15} \beta^{\prime}+\gamma^{\prime} \operatorname{ParentExp}_{i s, 15}+X_{i, 15} \theta^{\prime}+\varepsilon_{i s, 17}^{\prime}
$$

Similarly, equation (3) defines the probability to have aspirations to attend university ${ }^{3}$.

$$
A s p_{i s, 17}=\alpha_{1}^{\prime \prime} A s p_{i s, 15}+\alpha_{2}^{\prime \prime} G P A_{i s, 17}+\operatorname{Peers}_{i s, 15} \beta^{\prime \prime}+\gamma^{\prime \prime} \operatorname{ParentExp}_{i s, 15}+X_{i, 15} \theta^{\prime \prime}+\varepsilon_{i s, 17}^{\prime \prime}
$$

We use instrumental variables to estimate the parameters of the above simultaneous equations (2) and (3). The exclusion restriction for "High school GPA" is the change in the hours spent doing homework at home after school in the free time ( $\Delta$ Hours worked on HW) between age 15 and 17. The exclusion restriction for the aspirations variable is the change in the belief of whether the student thinks a university degree is required to work in the future job at age 30 ( $\Delta$ Think university required for future job). We acknowledge that in the levels, these two instruments may be driven by parents. Nevertheless, assuming parents affect students in a more or less consistent way through time, if we take the first difference for each of these two instruments the parental effect (individual effect for each student) would be differenced out. In this way " $\Delta$ Hours worked on HW" captures the change in effort as a result of an individual choice only; " $\Delta$ Think university required for future job" captures external information regarding the degree requirements or change in preferences for the future job at 30 years old. Table 4 shows the correlation coefficients between them and the endogenous variables. The first step regression estimates are presented in the bottom panel of Table 5. The aspirations variable has a high correlation with " $\Delta$ Think university required for future job" of 0.44 for both genders and the first step regression coefficients in Table 5 are significant at the $1 \%$

\footnotetext{
2 Regarding equation (1), since grades enter as predetermined variables from cycle 3, we do not have the endogeneity problem there and the outcome regressions are estimated by probit.

3 See figure 1 for a flow chart describing the relations involving these three equations. For simplicity, not all influences in equations (1), (2) and (3) are shown.
} 
confidence levels. This is a relevant instrument for the aspirations variable. Because it is based on future plans, it affects the student's motivation and thus aspirations for higher education. It may affect the academic performance during high school but that may only happen through channels of aspiration formation. The probability of achieving a high GPA is positively correlated to " $\Delta$ Hours worked on $\mathrm{HW}^{\prime}$ indicating that higher achievement comes with more effort. It is also highly significant at the conventional significance levels in the first step regressions for both genders. " $\Delta$ Hours worked on $\mathrm{HW}$ " has a direct effect on the grades and may affect aspirations indirectly only through grades.

Instrument validity, or the orthogonality of the instrument(s) with the error term, is another necessary condition that the instruments should satisfy. Since this is an assumption on which the instrumental variable (IV) estimator is based, it cannot be tested unless the number of IVs exceeds the number of endogenous variables. Instead, we refer to the Wald test of exogeneity to show that there is reason to believe that the instrumental variable estimator is appropriate. This is a Hausman type test of equality between the probit and ivprobit ${ }^{4}$ specifications. For the maximum likelihood variant with a single endogenous variable, the test asks whether the error terms in the structural equation and the reduced-form equation for the endogenous variable are correlated. If the test statistic is not significant, then there is not sufficient information in the sample to reject the null that there is no endogeneity. Table 5 contains the results. In all of the cases we reject, at $1 \%$ and $5 \%$ significance levels, the null that our variable is exogenous. So, since the Wald test provides evidence that probit and ivprobit specifications are significantly different, we base our discussion on the results obtained by using the instrumental variable estimator for the time the students are still in high school.

\section{Peer Effects}

\footnotetext{
4 The STATA command ivprobit is a maximum likelihood instrumental variable estimator used when both the endogenous and the dependent variables are binary.
} 
A strand of the peer effect literature, relevant to the present paper, analyses peer effects on the academic achievement of students, which is generally measured by standardized test scores or grade point average (GPA). Hoxby (2000), Sacerdote (2001), Lin (2010) find important influences of peers on students' GPA. Zimmerman (2003), Kramarz et al. (2008), Ammermueller and Pischke (2009), Boucher etal. (2010) all find statistically significant though small peer effects on standardized test scores. Hanushek and Woessman (2007) question the results they obtain by stating that the causal effect of peer variables remains ambiguous and Vigdor and Nechyba (2005) report no causal influence from peers on academic performance.

There are two major identification issues related to peer effect estimation discussed in the literature. The first issue is the endogenous peer-group selection and also the reason why it is often argued that many empirical studies find implausibly large peer effects. Students self-select into schools (or via parental decisions) based on their own characteristics, some of which are observable and others not (like ability). To mitigate the problem of sample selection in our estimates, we control for a set of variables measuring characteristics of both parents and children which also helped resolve the sample selection in Day (2009); Hanushek et al. (2003); Ding and Lehrer (2007). Among these, the PISA score is a measure for student's cognitive ability. Parental income, education, expectations, nurturing and monitoring behavior indices and family educational support are the most comprehensive indicators of the student's family environment and socio-economic background used in the literature. Additionally, the set of variables on school and teacher characteristics control for a very rich variety of factors related to teachers, students and educational resources that may affect the quality of the high schools. These variables help further the identification related to the endogenous group selection because they provide the parents with important signals regarding the quality level of the high school they choose for their child. Hence, conditional on the most important characteristics on which self-selection arises, grade-levels are likely to be constructed randomly. Also, even if one accepted the choice by parents to move to a certain neighborhood, it is the age of 
the child that determines the grade-year he will enter and consequently his classmates. Thus, as in Friesen and Krauth (2010), we think that, in this setting, it is plausible to assume that even where parents choose the school, the assignment to a grade-level within a school happens exogenously, based mostly on the age of the child. A certain amount of randomness is inherent in this process and is beyond the control of the parents and the child.

Further, in the event of self-selection, students may select into peer groups with similar unobserved characteristics that are stable, at least within the adolescence years while they go to the same school and live in the same neighborhood. We introduce the lagged grades and aspirations variable on the right-hand side of all our regressions to wipe out these common effects that otherwise would have been captured by the peer effects variable. This is based on the discussion of Hanushek et al. ( 2003, see page 531) who take the first difference of the dependent variable in order to eliminate the "historical influences" but state that it is equivalent to adding the lag of the outcome in the right-hand side of the regression. In this way no restriction is imposed on its coefficient. Hence, our peer effect estimates are free of self-selection and correlated effects after having conditioned on a variety of characteristics and factors based on which self-selection arises and accounting for the unobserved correlated effects.

The second issue is the reflection problem - differentiating between the simultaneity of the impact of peer group on the individual and the effect of the individual on the peer group. The reflection problem arises only if we try to estimate peer effects when the outcome of interest and the peer variable (constructed as an average of the same peer outcome) are concurrent because they may simultaneously affect each other. In our setting, the only way to avoid the simultaneity problem is to use the past values instead of the concurrent peer effect variables as in Hanushek et al. (2003). More precisely, we use the average of the PISA score at age 15 of current classmates. For the self-reported variables we also use two-year lagged values. Hanushek et al. (2003, pg.535) state that even though this strategy will identify the peer effect coefficients, it will provide a lower bound estimate. 


\section{Empirical Results}

Using data from YITS-A, Figure 2 shows the percentage of the students who aspire to go to university at age 15 and 17 by gender. It also shows university attendance rates at the age of 19 . The black bars indicate a positive response and the grey bars a negative response. This figure shows how aspirations at 17 are updated, conditional on age 15 aspirations and how this process leads up to university attendance. There are two points to take away from this chart. Firstly, for both genders the earlier they aspire to attend university the more likely they are to actually attend university after graduating from high school. Secondly, male students start with lower aspirations at age 15 . They are less likely to be persistent in their university aspirations, i.e. they are less likely to revise aspirations upward ${ }^{5}$ and more likely to revise aspirations downward than females ${ }^{6}$. As a result they are less likely to attend university at 19 (conditional on prior aspirations) than females ${ }^{7}$. This information confirms that separate investigations of the process leading up to PSE outcomes should be conducted for males and females.

The empirical results are analyzed differentiating between the two time periods that the data covers: the PSE years and the high school years. In Tables 2 to 5 we report marginal effects defined as the probability change in the occurrence of the positive outcome (as indicated by the dependent variable) caused by a unit change from the mean value of the referred variable, holding all independent variables at their mean levels. In the cases when the independent variable is a dummy variable, the marginal effect represents the change in probability from a discrete change of the

\footnotetext{
${ }^{5}$ At the age of $17,44 \%$ of the females who at 15 had not aspired to go to university updated their aspirations upwards, but only $31 \%$ of the males did so.

${ }^{6}$ On the other hand, $20 \%$ of the female students who at 15 had aspired to attend university updated their aspirations downward at 17 , whereas the corresponding number for males is $25 \%$.

${ }^{7}$ Out of the $69 \%$ of females that have aspirations to attend university at $15,80 \%$ of these maintain the same aspirations at 17 , most of whom (75\%) end up attending university at 19 . In the case of male students aged $17,75 \%$ of those who had university aspirations at 15 keep the same response, but out of this group only $70 \%$ actually go on to university. So, for the group of students who had university aspirations both at 15 and 17, the fraction of females attending university at 19 is 5 percentage points higher than that for males. From the female group that upgraded their aspirations (44\%) at 17, $47 \%$ of them actually attended university by the age of 19 . The corresponding number for the male group is $42 \%$. Even
} 
dummy variable from zero to one. In the case of the categorical variables, the marginal effects measure the impact on the probability of the positive outcome from moving one category up from the sample mean.

Even though not reported because of space limitations, we control in all specifications for a set of variables, which are listed in the footnote of each table. It is worthy of mentioning that among these variables, PISA score, "Parental education", "Parental income" and "Parents view of PSE important" have a positive effect on the probability of attending university. Having siblings that dropped out of high school and non-biological parents affects negatively the probability to attend university. For both genders, conditional on university attendance at age 21 , students with a rural background are more likely to graduate and attain the university degree by the age of 23 . Among the high school characteristics, the school size and the type of the school ("Government-independent private") have both a positive effect on the probability of PSE outcomes' realization. These variables have a similar effect on the probability to achieve a high GPA and on the probability to aspire to attend university. Other variables affecting the grades (but not PSE outcomes after controlling for high school grades) are "Teacher quality" and "Parents Nurturance Behavior", which have a positive influence. "Student-teaching staff ratio" and "Quality of School's Material Educational Resources", which measure the lack of potential time with the teacher and lack of educational resources, have a negative influence on the probability to achieve a high GPA in high school. These results all are in accordance with the findings in the literature. The full results are available on request.

\section{PSE Outcomes}

We investigate two outcome variables: the probability to have "Attended university" and the probability to have "Graduated university" (see Tables 2 and 3). Since it has been at least a year since students graduated from high school, simultaneity between high school grades (age 18) and

among the students that never aspired to go to university, females are 6 percentage points more likely to attend university than males. 
outcomes (age 19, 21 and 23) is unlikely. Hence, we analyze the probit specifications for these regressions.

Referring to Table 2, the lagged "Aspiration to attend university" variable has the highest marginal effect on the probability to attend university at all ages and among all variables that also are significant predictors of outcomes. Holding all independent variables at their means, having aspirations to attend university during high school increases the probability to attend university by 0.361 for females and 0.342 for males. This marginal effect increases to 0.518 for females and 0.439 for males at age 21 , and to 0.539 for females and 0.538 for males at age 23 . Thus the effect of the aspirations on the actual decision is substantial.

The influence of parental expectations on the decision to attend university is highly significant for all ages even after conditioning on parental education, income, "Family educational support", "Parents' nurturance behavior" and "Parents' monitoring behavior". The estimated effect for females decreases with age from 0.164 at age 19 to 0.129 and 0.128 at age 21 and 23 , respectively. The marginal effects are higher for males than females at all ages. They decrease from 0.254 at age 19 , to 0.186 at 21 and to 0.167 at age 23 .

It is interesting to see that the effect of "Friends smoke 15 " (at age 15) is still present (even after controlling for past aspirations and high school overall GPA) in the outcomes of male students at age 21 and female students at age 23. Associating with friends who smoke cigarettes decreases male's probability to attend university by 0.053 and that of females by 0.064 . Another peer variable influencing the probability of attendance is "Friends think going to PSE 15 ". This variable influences males students positively by increasing their probability to attend university by 0.109 at age 19 and by 0.150 at age 23 given a one category increase above the mean. Regarding peer cognitive ability ${ }^{8}$,

\footnotetext{
${ }^{8}$ One might argue that due to the fact that these two sets of peer variables are by construction different (identification issues arise for each), including both sets simultaneously into the regressions might be driving our results. We repeated the analysis by including each set of peer variables separately and the results are quantitatively and qualitatively similar to the ones presented in the paper. These tables are available on request.
} 
"Grade-level average PISA", in most of the regressions is insignificant, after controlling for grades and aspirations during high school. So, it seems that after graduating from high school female students are mainly affected by parental expectations, whereas male students are affected by both parental expectations and their peers' aspirations and attitudes.

In the last two columns of Table 2, we show the regression results for the outcome "Graduated university" conditional on the lag of "Attended university". Females' probability to graduate is negatively affected by "Friends smoke 15 " and decreases by 0.039 . On the other hand, for male students parental expectations and "Friends think completing HS is important 15 " increase their probability to graduate by 0.050 and 0.032 , respectively.

We took a further step and estimated the reduced form model for three distinct quartiles of the parental income distribution: the lowest $25 \%$, the middle $50 \%$ and the top $25 \%$. We did this exercise only for the last cycle of the data, when the students are 23 years old, because even those that choose to have a year off after high school should, by this age, be enrolled in a PSE program if they intend to do so. The results are displayed in Table 3. Aspirations to attend university have an important effect for all income groups and genders. We note that, except for female students of high-income families, the parental expectations variable plays an important role in increasing the probability of university attendance for both genders. "Friends smoke 15 " has a negative effect on the probability of the outcome of females only. This effect is nonlinear and monotonically decreasing as we go from low to middle and lastly to high-income families. The marginal effect for the lower end of the income distribution (-0.094) is almost twice as big as the one in the higher end $(-0.049)$. This suggests that females of low-income families are more vulnerable to friends with negative attitude or rebellious behavior, than the female students in the other income groups. Friends with aspirations to go to PSE positively affect students from high-income families. Notice that, conditional on past aspirations, only male students of high-income families are influenced by peers. Male students from low and middle-income families are only affected by parental expectations. 
We note that the university attendance gap (the difference between the "Mean Y" in Table 3 between female and male students for each income category) is highest for the low-income family students (16.4 percentage points) and much lower for the middle (9.1) and high-income (10.6) family students. So, any attempt to balance the gender gap, should be concentrated on the lowincome group students in particular.

The marginal effects of the family environment and peers on the PSE outcomes can be interpreted as additional effects, i.e. a marginal effect in addition to the effect that these variables have on a student's overall high school GPA and aspirations during the high school years, which themselves have strong effects on the decision to attend university. Next, we analyze role of family and friends in the aspirations formation process during high school.

\section{High School Years}

In this subsection we estimate the effect of the own, peer and parental variables on the probability of achieving a GPA higher than $70 \%$ and the probability to have university aspirations at age 17 . The results are shown in Table 5. The coefficients of the endogenous variables increase considerably after the instrumental variable approach is used in both grade and aspiration regressions. They are highly significant regardless of the estimator used and conditional on the measure for cognitive ability. For the reasons discussed in Section 3, while interpreting these results we focus mainly on the ivprobit specifications.

In both high school grades and aspirations, parental expectations have a statistically insignificant effect but the effect of peers seems to prevail for both genders. Having friends with a smoking habit decreases the probability to achieve a high school GPA higher than $70 \%$ by 0.021 for females and by 0.034 for males. An increase in classmates average cognitive ability measure increases the students' probability to do well in school by 0.047 for females and by 0.131 for males. Similar to the grades equation, female students probability to have university aspirations is affected positively by 
the level of cognitive ability of their classmates as measured by the average PISA score. Male student's aspirations are not affected by classmates, but by the effect of the closest friends. In this regression, "Friends smoke 15 " has a positive effect of 0.039 on the probability of aspiring to go to university for males.

\section{Conclusion}

In this paper we use a rich Canadian dataset to analyze the role of a number of variables, including parental influences and peer effects, in determining the formation of aspirations about further education and grade achievements of high school students. We then investigate how these aspirations affect the probability to attend university and the probability to complete a university degree. Different from research in this area, which generally examines the issue based on a point in time and with data from a single institution (school or university), we are able to conduct a longitudinal analysis with data representative of the Canadian youth.

We conclude that the individuals' high school GPA and the aspirations for further education held during high school are important determinants of the probability to attend university. Conditional on a measure for cognitive ability, having a GPA higher than $70 \%$ increases the probability of going to university by about 0.239 for females and 0.316 for males. Having aspirations to attend university during high school, increases the probability of attendance by 0.361 for females and 0.342 for males at age 19. At age 21 and 23 the marginal effects are higher in magnitude. The probability of attending university after graduating from high school for male students is affected both by parental expectations and peer effects above and beyond the effect that these variables have on the evolution of the overall GPA and on the evolution of aspirations during the high school years. Female students' probability to attend university is affected (through their direct channel) by parental expectations only until age 21 , but by both peers and parents at 23 years old. Even though the peer variables' marginal effects are relatively small, the marginal effects from the parental expectations 
are substantial; the increase in probability of attendance varies with age between 0.129 and 0.164 for females and between 0.167 and 0.254 for males. When we split the sample by income group, we find that the peer effect on females' probability to attend university diminishes as we move from lower to higher income group families. In the case of males, only those from the high-income group are affected by peer aspirations to attend PSE. Regarding the high school period, after correcting for the simultaneity between grades and aspirations, we find that having aspirations to attend university is at least as important as cognitive ability in increasing the probability of high academic performance. Students are affected more by their close friends and classmates than by their parents, teachers and high school characteristics.

From the perspective of a policy goal to increase PSE attendance, it would appear that a strong effect could be created by exploiting the influence that parents have on children by providing information about the advantages of PSE not only to students but also to their parents. Having parents and their children attend the same information meetings could be very productive as this would influence not only the expectations of both parents and children but reinforce the children's belief about their parents interest in possible PSE attendance. It is important that parents are aware of the difference it makes in the lifestyle (e.g. higher income) of their children if they complete a degree from a university. These students will have a peer effect on their friends, creating a social multiplier effect along with the direct effect on the reference child. Based on our results, the policy measure should focus mainly on the children of low-income families because it is likely that the impact will be larger in this group. Note, also, that this group has a higher gender gap in university attendance than the middle and high-income group. Of course, it may be difficult to target by family income for a given school. But additional resources for such a program could be made available for schools in lower income districts. 


\section{Appendix}

\section{Variable Definitions}

High School GPA Dummy Variable. 1 if the students reports to have a high school grade point average (GPA) up to the time of interview within the range of $70-79 \%$ or higher.

Aspirations to attend university Dummy Variable. 1 if the highest level of education respondent think he/she will get/would like to get is a university diploma or certificate below Bachelor's, a Bachelor's Degree or higher (or one university degree or more than one university degree for cycles 1,2); 0 otherwise.

Attended university Dummy Variable. 1 if response to the question "Highest level of PSE taken across all programs and institutions?" is a university diploma or certificate below Bachelor's, Bachelors degree or higher, 0 otherwise. The respondents may have graduated from this level, may still be in the program or maybe left the program.

Graduated university Dummy Variable. 1 if response to the question "What is the highest degree you have attained?" is a university diploma or certificate below Bachelor's, a Bachelor's degree or higher; 0 otherwise.

Hours worked on HW Categorical Variable. Equals 0 if "No time" spent working on homework outside class during free periods and at home within a week; 1 if "less than 1 hour a week"; 2 if "1-3 hours a week"; 5.5 if "4-7 hours a week"; 11 if " 8-14" hours a week; 15 if "more than 15 hours a week".

PISA score Programme for International Student Assessment (PISA) reading test score expressed in per 100 points.

Think university required for future job Dummy Variable. 1 if response to the question "How much education do you think is needed for this type of work? One university degree? or More than one university degree?" is "Yes"; 0 otherwise. Covers respondents who have decided what type of career of work they would be interested in having when they will be about 30 years old.

Grade-level average GPA The portion of students in the same grade-level that indicate to have an overall high school grade point average (GPA) of $70 \%$ or higher excluding the reference student.

Grade-level average aspirations The portion of students in the grade-level that indicate to have aspirations to attend university excluding the student.

Grade-level average PISA 15 The average PISA score of the students in the same grade-level excluding the reference student.

Friends smoke 15 Categorical Variable. Equals 0 if student response to the question "Think about your closest friends. How many of these friends smoke cigarettes?" is "None of them"; 1 if "Some of them"; 2 if "Most of them"; 3 if "All of them".

Friends think it okay to work hard ${ }_{15}$ Categorical Variable. Equals 0 if student response to the question "Think about your closest friends. How many of these friends think it's okay to work hard at school? " is "None of them"; 1 if "Some of them"; 2 if "Most of them"; 3 if "All of them".

Friends think completing HS is important 15 Categorical Variable. Equals 0 if student response to the question "Think about your closest friends. How many of these friends think completing high school is very important?" is "None of them"; 1 if "Some of them"; 2 if "Most of them"; 3 if "All of them".

Friends think going to PSE $_{15}$ Categorical Variable. Equals 0 if student response to the question "Think about your closest friends. How many of these friends are planning to further their education or training after leaving high school?" is "None of them"; 1 if "Some of them"; 2 if "Most of them"; 3 if "All of them".

Sibling drop-out Dummy Variable. 1 if any of the child's brother's or sisters is a high school drop-out; 0 otherwise.

Parent(s) immigrant 1 if at least one the parents has ever been a landed immigrant to Canada; 0 otherwise.

Parental income Variable indicating the combined (respondent and spouse/partner) total income divided by the number of the household members. Total income is derived from a sum of the nine income sources collected during the Parent interview. They are Wages and Salaries before deductions, including bonuses, tips and commissions; Net Income from Farm and Non-Farm Self-employment (after expense and before taxes); Employment Insurance benefits (before deduction); Canada Child Tax Benefits and provincial child tax benefits or credits (including Quebec Family Allowance); Social Assistance (welfare) and Provincial Income Supplements; Support program received, such as spousal and child support; Other Government Sources, such as Canada or Quebec Pension Plan Benefits, Old Age Security 
Pension, or Workers' Compensation Benefits; Goods and Service Tax Credit/Harmonized Tax Credit received in 1999; and Other Non-Government sources including dividends, interest and other investment income, employment pension, RRIFs and annuities, scholarships, and rental income.

Non-birth parent Dummy Variable. 1 if the parent is not by birth (i.e. by adoption, foster, step parent or guardian); 0 otherwise.

Parental education Father university Dummy Variable: 1 if the father has a university certificate or diploma below Bachelor's, a Bachelor's Degree or higher; 0 otherwise. Mother university Dummy Variable: 1 if the mother has a university certificate or diploma below Bachelor's, a Bachelor's Degree or higher; 0 otherwise.

Parental expectations Dummy Variable. 1 if response of the parent to the question "What is the highest level of education that you hope child will get?" is "One university degree" or "More than one university degree"; 0 otherwise.

Parents view of PSE important Categorical Variable. Equals 0 if response of the child to the question "How important is it to your parent(s) that you get more education after high school?" is "Not important at all", "I don't know", "No such person"; 1 if "Slightly important"; 2 if "Fairly important"; 3 if "Very important". In cycle 1 we may differentiate between mother and father.

Parents' nurturance behavior Parent's reports on the frequency with which parents: praise child; listen to child's ideas and options; make sure child knows that they are appreciated; speak of good things those children does; and, seem proud of the things child does. A YITS scale variable is derived from this information.

Parents' monitoring behavior Parent's reports on the frequency that the parent: know where child goes at night; know what child is doing when he/she goes out; and, know who child spends time with when he/she goes out. A YITS scale variable is derived from this information.

Family educational support Student's reports on the frequency that his/her parents and siblings work with them on their schoolwork. A PISA index is then derived.

Percent females This index is the ratio between the number of girls and the total enrollment (the number of boys plus number of girls)- i.e., the number of girls in the school divided by the total enrollment.

School size The total enrolment in the school.

Teacher quality Number of full-time teachers who have a third level qualification (i.e. a BA degree with a major in English language and literature) plus 0.5 times the number of part-time teachers with a third level qualification divided by the total number of teachers in a school. The third level qualifications counted are a degree in English and literature, in mathematics and science (chemistry, physics, biology or earth science).

Government-independent private Dummy Variable. 1 if the school is government-independent private, 0 otherwise. Government-independent private schools were coded as 1 , if the school principal reported that the school was controlled and managed by a non-governmental organization (e.g., a church, a trade union or a business enterprise) or if its governing board consisted mostly of members not selected by a public agency, where it received less than 50 per cent of its core funding from government agencies.

Instructional time Instructional time for 15-year-old students in the school and derived hours of schooling per year.

Quality of school physical infrastructure School principals' reports on the extent to which learning by 15 -yearolds in their school was hindered by: poor condition of buildings; poor heating and cooling and/or lighting systems; and, lack of instructional space. An index is derived from the above information.

Quality of schools' material educational resources School principals' reports on the extent to which learning by 15-year-olds in their school was hindered by: lack of instructional material; not enough computers for instruction; lack of instructional materials in the library; lack of multi-media resources for instruction; inadequate science laboratory equipment; and, inadequate facilities for the fine arts. An index of the quality of schools' educational resources is derived after.

Teacher-related factors affecting school climate Principals' reports on the extent to which the learning by 15 -yearolds was hindered by: low expectation of teachers; poor student-teacher relations; teachers not meeting individual students' needs; teacher absenteeism; staff resisting change; teacher being too strict with students; and students not being encouraged to achieve their full potential. An index is derived for principals' perceptions of teacher-related factors affecting school climate.

Student-related factors affecting school climate Principals' reports on the extent to which learning by 15 -year-olds in their school was hindered by: student absenteeism; disruption of classes by students; students skipping classes; students lacking respect for teachers; the use of alcohol or illegal drugs; and students intimidating or bullying other 
students. An index is derived for principals' perceptions of student-related factors affecting school climate.

Teachers' morale and commitment The extent to which school principals agreed with the following statements: the morale of the teachers in this school is high; teachers work with enthusiasm; teachers take pride in this school; and, teachers value academic achievement. An index was derived for principals' perceptions of teachers' morale and commitment.

Teacher shortage The principals' views on how much learning by 15-year-old students was hindered by: shortage or inadequacy of teachers in general and in each type of courses in language, math, and science. An index is derived from these information.

Student-teaching staff ratio This index is the school size divided by the total number of teachers (part-time teachers contribute 0.5 and full-time contribute 1.0).

Residence region indicators Rural Dummy Variable: Indicator of rural vs. urban geography, based on the Statistical Area Classification, based on the 1996 Census geography equals 1 if "Rural"; 0 if "Urban". Atlantic Dummy Variable: 1 if province of the student is either of the Newfoundland, Prince Edward Island, Nova Scotia or New Brunswick; 0 otherwise. Manitoba or Saskatchewan Dummy Variable, Alberta Dummy Variable, British Columbia Dummy Variable.

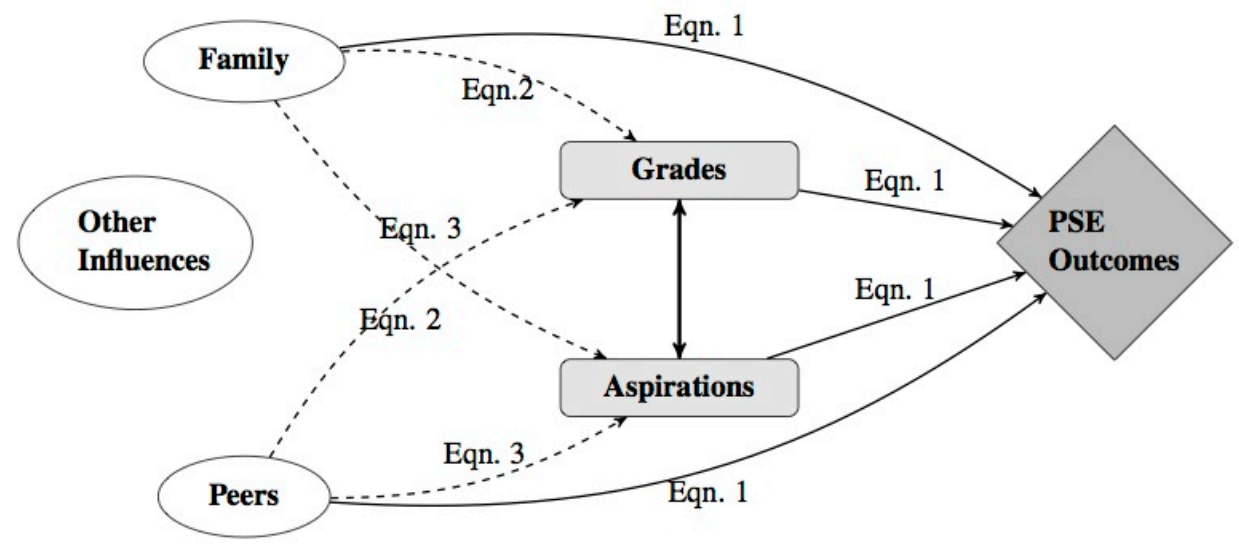

Figure 1. Model set-up 


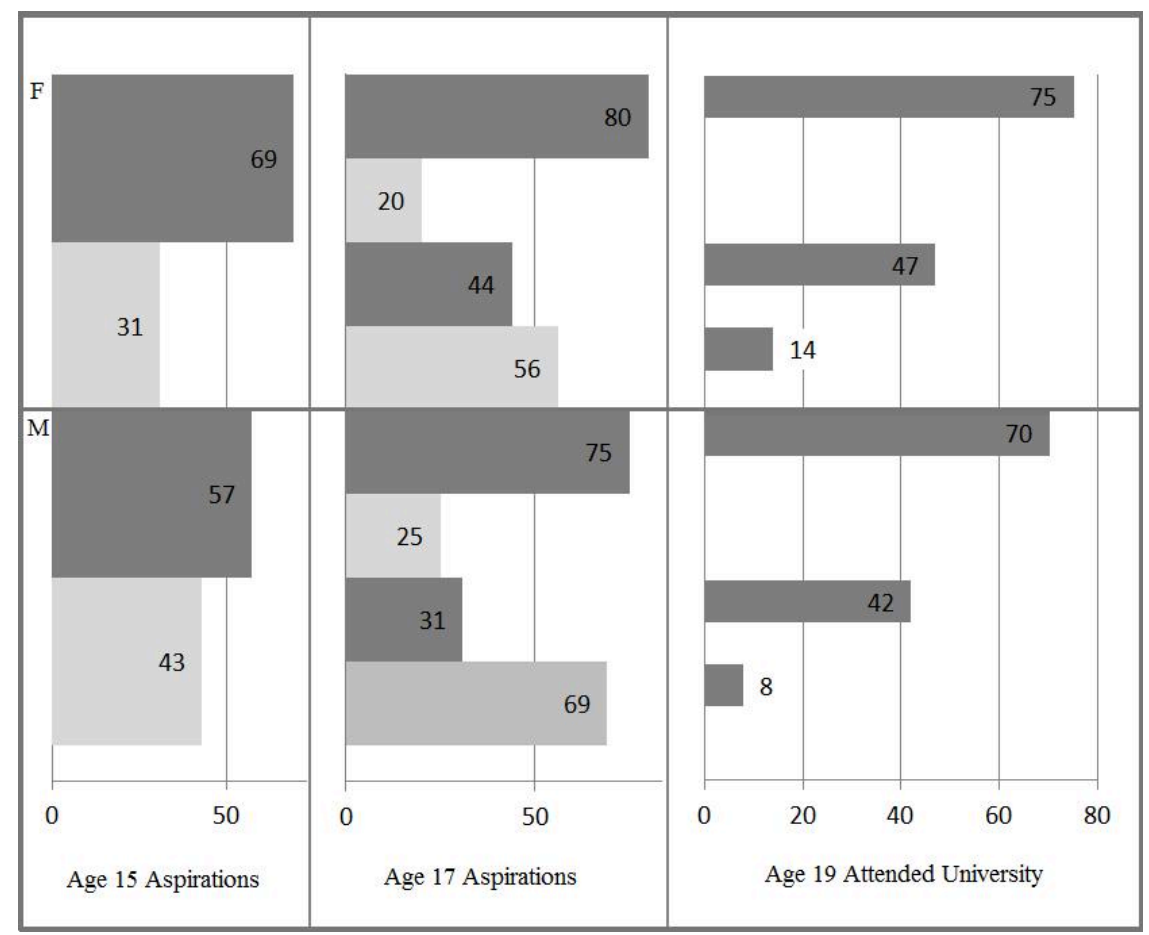

Figure 2. Percentage aspiring to attend a university program conditional on past aspirations

\section{TABLE 1}

Reference time and age of the respondents by cycle in YITS-A

\begin{tabular}{cccc}
\hline Cohort A & Age & Reference Time Period & Time of the Interview \\
\hline Cycle 1 & 15 & January 1998-December 1999 & January 2000-April 2000 \\
Cycle 2 & 17 & January 2000-December 2001 & January 2002-April 2002 \\
Cycle 3 & 19 & January 2002-December 2003 & January 2004-April 2004 \\
Cycle 4 & 21 & January 2004-December 2005 & January 2006-April 2006 \\
Cycle 5 & 23 & January 2006-December 2007 & January 2008-April 2008 \\
\hline
\end{tabular}

TABLE 2 


\section{Peer and parental influences on probability to attend university at age of $19,21 \& 23$}

\begin{tabular}{|c|c|c|c|c|c|c|c|c|}
\hline \multirow{3}{*}{ Attended University } & \multicolumn{6}{|c|}{ Attended University } & \multirow{2}{*}{\multicolumn{2}{|c|}{$\begin{array}{c}\text { Graduated University } \\
\text { Age } 23\end{array}$}} \\
\hline & \multicolumn{2}{|c|}{ Age 19} & \multicolumn{2}{|c|}{ Age 21} & \multicolumn{2}{|c|}{ Age 23} & & \\
\hline & $\mathrm{F}$ & M & $\mathrm{F}$ & M & $\mathrm{F}$ & M & $\mathrm{F}$ & M \\
\hline High School GPA & $0.239 * * *$ & $0.316^{* * *}$ & $0.228 * * *$ & $0.267 * * *$ & $0.112 *$ & 0.069 & $0.157 * * *$ & 0.062 \\
\hline Aspirations to attend university & $0.361 * * *$ & $0.342 * * *$ & $0.518 * * *$ & $0.439 * * *$ & $0.539 * * *$ & $0.538^{* * *}$ & $0.111 * * *$ & $0.148 * * *$ \\
\hline Parental expectations $_{15}$ & $0.164 * * *$ & $0.254 * * *$ & $0.128 * * *$ & $0.186^{* * *}$ & $0.129 * * *$ & $0.167 * * *$ & -0.001 & $0.050 * *$ \\
\hline Friends smoke 15 & 0.001 & -0.029 & -0.028 & $-0.053 * *$ & $-0.064 * * *$ & -0.029 & $-0.039 * *$ & 0.002 \\
\hline $\begin{array}{l}\text { Friends think it okay to work hard }{ }_{15} \\
\text { Friends think completing HS is }\end{array}$ & 0.015 & 0.045 & 0.010 & -0.027 & 0.035 & -0.008 & -0.004 & -0.009 \\
\hline important $_{15}$ & 0.001 & -0.011 & 0.021 & -0.009 & 0.017 & -0.002 & 0.001 & $0.032 * *$ \\
\hline Friends think going to $\mathrm{PSE}_{15}$ & 0.069 & $0.109 *$ & 0.084 & 0.118 & 0.043 & $0.150 * * *$ & 0.027 & -0.033 \\
\hline Grade-level average PISA $_{15}$ & -0.028 & -0.038 & -0.026 & 0.033 & -0.055 & 0.011 & -0.011 & 0.016 \\
\hline Sample size & 2271 & 1694 & 2816 & 2258 & 2358 & 1932 & 2258 & 1815 \\
\hline Pseudo- $\mathrm{R}^{2}$ & 0.359 & 0.359 & 0.476 & 0.459 & 0.534 & 0.504 & 0.369 & 0.358 \\
\hline
\end{tabular}

Significance levels: $0.01^{* * *}, 0.05^{* *}, 0.10^{*}$. The table presents probit marginal effects evaluated at the mean. Even though not reported in the tables because of space constraints, we control in all specifications for "PISA score", "Parent(s) immigrant", "Parental income", "Non-birth parent", "Parents' view of PSE important", "Parents' nurturance behavior", "Parents' monitoring behavior", "Family Educational support", "Sibling drop-out", "Parental education", "Percent females", "School size", "Teacher quality", "Government-independent private", "Instructional time", "Quality of school physical infrastructure", "Quality of schools" material educational resources", "Teacher-related factors affecting school climate", "Student-related factors affecting school climate", "Grade-level average aspirations 15 ", "Teachers' morale and commitment", "Teacher shortage", "Student-teaching staff ratio", and "Residence region indicators". In the last two columns labeled "Graduated University" we also control for "Attended University" at age 21 (see Appendix for definitions). 
TABLE 3

Peer and parental influences on probability to attend university at age 23 by income distribution

\begin{tabular}{|c|c|c|c|c|c|c|}
\hline \multirow[t]{2}{*}{$\mathrm{Y}=$ Attended University } & \multicolumn{2}{|c|}{ Lowest $25 \%$} & \multicolumn{2}{|c|}{ Middle $50 \%$} & \multicolumn{2}{|c|}{ Top $25 \%$} \\
\hline & $\mathrm{F}$ & M & $\mathrm{F}$ & M & $\mathrm{F}$ & M \\
\hline High School GPA & -0.005 & 0.105 & $0.318 * * *$ & 0.044 & 0.021 & $0.163 *$ \\
\hline Aspirations to attend university & $0.439 * * *$ & $0.538 * * *$ & $0.602 * * *$ & $0.693 * * *$ & $0.495 * * *$ & $0.483 * * *$ \\
\hline Parental expectations $_{15}$ & $0.138 * *$ & $0.237 * *$ & $0.193 * * *$ & $0.138 * *$ & 0.062 & $0.139 * *$ \\
\hline Friends smoke $_{15}$ & $-0.094 * * *$ & -0.014 & $-0.071 * *$ & -0.062 & $-0.049 * *$ & -0.001 \\
\hline Friends think it okay to work hard ${ }_{15}$ & 0.025 & -0.031 & 0.054 & 0.025 & 0.023 & 0.002 \\
\hline Friends think completing HS is important 15 & -0.005 & 0.045 & 0.044 & -0.012 & -0.013 & -0.055 \\
\hline Friends think going to $\mathrm{PSE}_{15}$ & 0.019 & 0.143 & 0.023 & 0.081 & $0.123 *$ & $0.267 * * *$ \\
\hline Grade-level average PISA $_{15}$ & -0.065 & 0.033 & -0.025 & -0.036 & -0.051 & 0.053 \\
\hline Sample size & 496 & 370 & 1203 & 990 & 701 & 579 \\
\hline Pseudo- $\mathrm{R}^{2}$ & 0.549 & 0.525 & 0.609 & 0.563 & 0.535 & 0.513 \\
\hline Mean Y & 0.661 & 0.497 & 0.649 & 0.558 & 0.747 & 0.641 \\
\hline Gender gap & 0.164 & & 0.091 & & 0.106 & \\
\hline
\end{tabular}

Significance levels: $0.01 * * *, 0.05^{* *}, 0.10^{*}$.The table presents probit marginal effects evaluated at the mean. Even though not reported in the tables because of space constraints, we control in all specifications for "PISA score", "Parent(s) immigrant", "Parental income", "Non-birth parent", "Parents' view of PSE important", "Parents' nurturance behavior", "Parents' monitoring behavior", "Family Educational support", "Sibling drop-out", "Parental education", "Percent females", "School size", "Teacher quality", "Government-independent private", "Instructional time", "Quality of school physical infrastructure", "Quality of schools' material educational resources", "Teacherrelated factors affecting school climate", "Student-related factors affecting school climate", "Grade-level average aspirations 15 ", "Teachers' morale and commitment", "Teacher shortage", "Student-teaching staff ratio", and "Residence region indicators" (see Appendix for definitions).

TABLE 4

Correlation coefficients between iv and the endogenous variables at age 17

\begin{tabular}{rlrcc}
\hline & \multicolumn{2}{c}{ High School GPA } & \multicolumn{2}{c}{ Aspirations to attend university } \\
& F & M & F & M \\
\hline $\begin{array}{rlll}\Delta \text { Hours worked on HW } \\
\text { TThink university required for future job }\end{array}$ & 0.062 & 0.069 & & \\
\hline
\end{tabular}




\section{TABLE 5}

Peer and parental influences on high school outcomes age 17

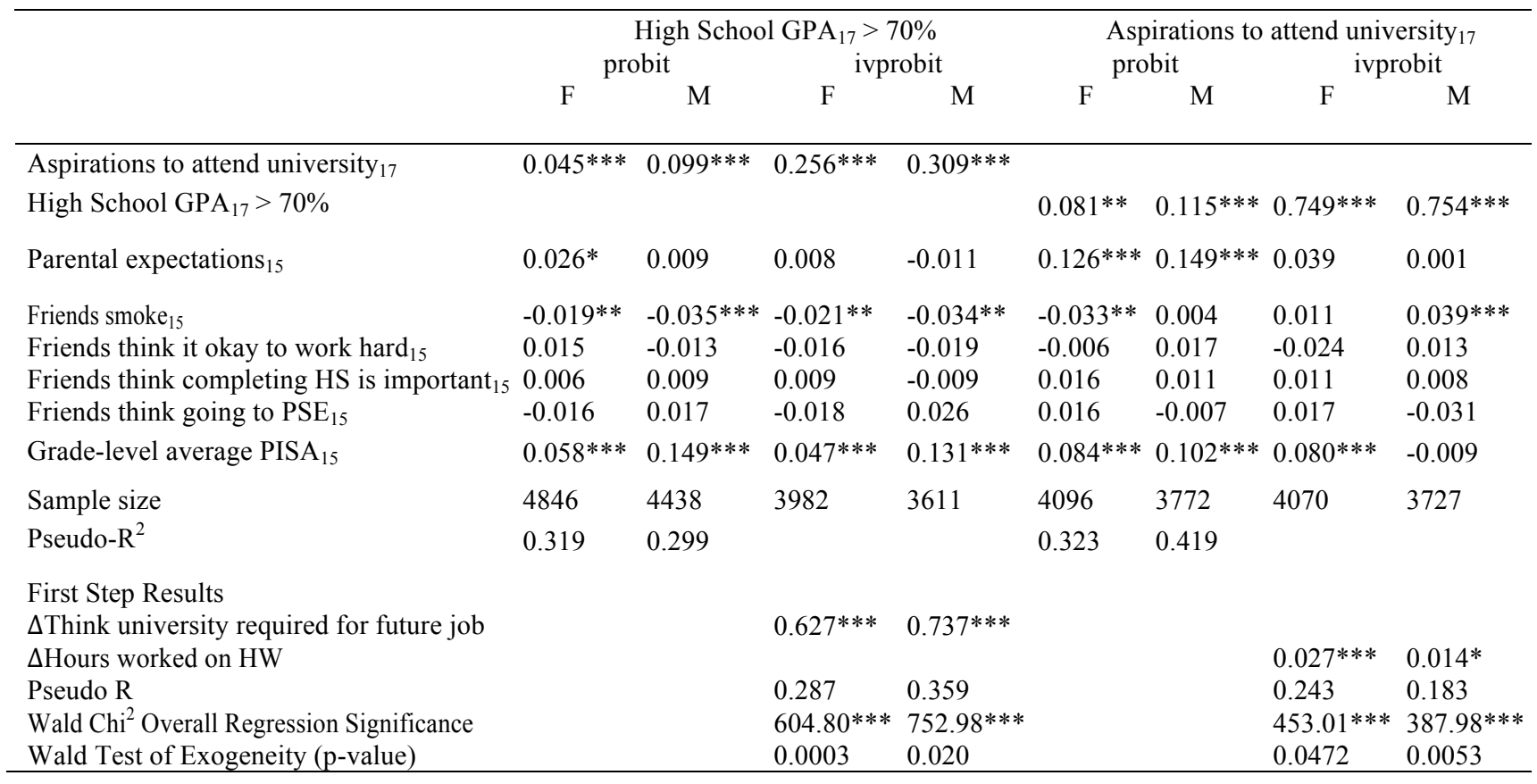

Significance levels: $0.01 * * *, 0.05^{* *}, 0.10^{*}$. The table presents probit and ivprobit marginal effects evaluated at the mean. Even though not reported in the tables because of space constraints, we control in all specifications for "PISA score", "Parent(s) immigrant", "Parental income", "Non-birth parent", "Parents' view of PSE important", "Parents' nurturance behavior", "Parents' monitoring behavior", "Family Educational support", "Sibling drop-out", "Parental education", "Percent females", "School size", "Teacher quality", "Government-independent private", "Instructional time", "Quality of school physical infrastructure", "Quality of schools" material educational resources", "Teacher-related factors affecting school climate", "Student-related factors affecting school climate", "Grade-level average $\mathrm{GPA}_{15}$ ", "Grade-level average aspirations 15 ", "Teachers' morale and commitment", "Teacher shortage", "Student-teaching staff ratio", and "Residence region indicators" (see Appendix for definitions).

\section{References}

Ammermueller, A., \& Pischke, J.-S. (2009). Peer effects in European primary schools: Evidence from progress in international reading literacy study. Journal of Labor Economics , 27, 315-348. Black, S. E., Devereux, P. J., \& Salvanes, K. G. (2010). Under pressure? The effects of peers on outcomes of young adults. UCD Centre for Economic Research, Working Paper Series, WP10/16.

Boucher, V., Bramoulle, Y., Djebbari, H., \& Fortin, B. (2010, January). Do peers affect student achievement? Evidence from Canada using group size variation. Discussion Paper 4723, Institute for the Study of Labor, IZA, P.O. Box 7240, 53072 Bonn, Germany.

Christofides, L. N., Hoy, M., Li, Z. J., \& Stengos, T. (2008). The evolution of aspirations for university attendance. In R. Finie, R. E. Mueller, A. Sweetman, \& A. Usher (Eds.), Who Goes? Who Stays? What Matters? Accessing and Persisting in Post-Secondary Education in Canada (pp. 109-134). Queen's School of Policy Studies, McGill - Queen's University Press. 
Cooley, J. (2007, November). Alternative mechanisms of peer achievement spillovers: Implications for identification and policy. WCER Working Paper No.2008-08, Madison: University of Wisconsin-Madison, Wisconsin Center for Education Research .

Day, K. (2009). The effect of high school resources on investment in post-secondary education in Canada. Unpublished Manuscript .

Ding, W., \& Lehrer, S. F. (2007). Do peers affect student achievement in China's secondary schools? The Review of Economics and Statistics , 89 (2), 300-312.

Finnie, R., \& Mueller, R. (2008). The backgrounds of Canadian youth and access to postsecondary education: New evidence from the Youth in Transition Survey. In R. Finnie, R. E. Foley, K., Gallipoli, G., \& Green, D. A. (2009, September). Ability, parental valuation of education and the high school drop-out decision. IFS Working Paper W09/21, Institute for Fiscal Studies.

Frenette, M. (2009, October). Career goals in high school: Do students know what it takes to reach them and does it matter? Research Paper Series 11F0019M No.320, Statistics Canada, Social Analysis Division, 24-J, R.H. Coats Building, 100 Tuney's Pasture Driveway, Ottawa KlA0T6 .

Frenette, M., \& Zeman, K. (2007, September). Why are most university students women? Evidence based on academic performance, study habits and parental influences. Analytical Studies-Research Paper Series 11 F0019 No.303, Statistics Canada, Bussiness and Labour Market Analysis, 24-J, R.H. Coats Building, 100 Tuney's Pasture Driveway, Ottawa K1A0T6. Friesen, J., \& Krauth, B. (2010). Sorting, peers, and achievement of aboriginal students in British Columbia. Canadian Journal of Economics , 43, 1273-1301.

Hanushek, E. A., Kain, J. F., Markman, J. M., \& Rivkin, S. G. (2003). Does peer ability affect student achievement? Journal of Applied Econometrics , 18, 527-544.

Hanushek, E. A., \& Woessman, L. (2007, February). The role of school improvement in economic development. Working Paper 1911, CESIFO. Category 5: Fiscal Policy,

Macroeconomics and Growth .

Hoxby, C. (2000). Peer effects in the classroom: Learning from the gender and race variation. NBER Working Papers No. 7867 .

Jacob, B. A. (2002). Where the boys aren't: Non-cognitive skills, returns to school and the gender gap in higher education. Economics of Education Review, 21, 589-598.

Johnson, D., \& Rahman, F. (2005). The role of economic factors, including the level of tuition, in individual university participation decisions in Canada. Canadian Journal of Higher Education, 35 (3), 83-99.

Knighton, T., \& Mirza, S. (2002). Postsecondary participation: The effects of parents' education and household income. Education Quarterly Review , 8 (3), 25-32.

Kramarz, F., Machin, S., \& Ouazad, A. (2008). What makes a test score? The respective contributions of pupils, schools, and peers in achivement in english primary education.

Discussion Paper 3866, IZA .

Lee, L. (2007). Identification and estimation of econometric models with group interactions, contextual factors and fixed effects. Journal of Econometrics , 140 (2), 333-374.

Lin, X. (2010). Identifying peer effects in student academic achievement by spatial autoregressive models with group unobservables. Journal of Labor Economics , 28 (4), 825-860. Mueller, A. Sweetman, \& A. Usher (Eds.), Who Goes? Who Stays? What Matters? Accessing and Persisting in Post-Secondary Education in Canada (pp. 79-108). Queen's School of Policy Studies, McGill - Queen's University Press. 
Sacerdote, B. (2001, May). Peer effects with random assignments: Results for Dartmouth roommates. The Quarterly Journal of Economics , 681-704.

Vigdor, J. a. (2005). Peer effects in North Carolina public schools. Unpublished Manusript . Zimmerman, D. J. (2003). Peer effects in academic outcomes: Evidence from a natural experiment. The Review of Economics and Statistics , 85 (1), 9-23.

Zhao, J., Corak, M., \& Lipps, G. (2003). Family income and participation in post-secondary education. Analytical Studies Branch, Research Paper Series 2003210e, Statistics Canada . 